\title{
Improving early childhood literacy and school readiness through Reach Out and Read (ROR) program.
}

\author{
Kripa Thakur, Sathyanarayan Sudhanthar, Yakov Sigal, Nina Mattarella \\ Dept. of Pediatrics and Human Development, College of Human Medicine, Michigan State University, USA
}

\begin{abstract}
Reach out and Read program (ROR) prepares young children to succeed in school by partnering with physicians and training them in handing out age appropriate books and to counsel parents about the importance of reading aloud to their children. Children served by ROR enter kindergarten with stronger vocabulary and language skills. The aim of this project was to improve the rate of distribution of books and physician advice about reading, to the families at each well child visit in the age range of six months to five years. This Quality Improvement (QI) project was conducted in a large inner-city pediatric residency clinic serving a lower socio-economic status under-served population. After reviewing the data from the past two years, we noticed that there was a tremendous drop in the percentage of books handed out at well visits and advice given to parents about benefits of reading aloud and self-reporting of parents reading to their child for four or more days in a week. Two goals were established: 1. To increase the rate of distributing books at every well child visit (WCV) from six months to five years of age by at least $80 \%$. 2. To improve the rate of counseling given by the resident physicians to the families by at least $75 \%$. A workflow was created to efficiently distribute books at well visits. A presentation about the ROR program was attended by all the physicians and residents. Reading tips in each exam room were posted to serve as a reminder for all providers and for the parents. A three question survey was collected from the families at the end of their well visit. A total of 210 surveys were collected from parents over a six month period. The percentage of handing out books at all well child visits increased from $30 \%$ to $96 \%$. The rate of providers giving advice about the benefits of reading increased from $26 \%$ to $87 \%$. The percentage of parents reading to their child greater than four days per week increased from $56 \%$ to $80 \%$. Reading aloud is widely recognized as the single most important activity leading to literacy acquisition. With the above interventions, families participating in the ROR model at our clinic were more likely to read to their children, more likely to report reading aloud at bedtime, and to read aloud four or more days per week.
\end{abstract}

\section{Problem}

The Ingham County Health Department Well-Child Clinic (ICHDWCC) in Lansing, Michigan is a Pediatric primary care practice serving about 6500 children in the community. More than $95 \%$ of the population served by this clinic, is an under-served population with Medicaid insurance. The clinic is also a designated teaching clinic for the Pediatric residents from Michigan State UniversitySparrow Hospital. Residents serve as the primary care providers, supervised by faculty from Michigan State University. A few years ago, Reach Out and Read (ROR), a national program was started in this clinic by physician champions. The goal of this program is to improve the reading ability of children and help make them kindergarten ready by distributing books during every well child visit starting from six months to five years of age and to encourage primary care physicians to counsel good reading habits with families. It also advocates that parents read more than four days a week for 20-30 minutes to their child. Internal review among the staff and the providers yielded a great variability in the distribution of the books and very few physicians were counseling about reading habits to the family. This was a two-fold problem because families served by the clinic are an under-served population and typically are not able to afford the cost of buying age-appropriate books for their children and the children served by the clinic were more prone to have reading problems and the risk of not being ready for kindergarten.

\section{Background}

There are nearly 5000 ROR programs across the United States and each year about 6.5 million books are being distributed. In the state of Michigan, there are only about 148 of these programs serving 89,600 children annually.[1] Early Brain and Child Development (EBCD) is an important priority for American Academy of Pediatrics (AAP). The academy supports physicians working closely with families to promote EBCD particularly in the first 1000 days of life of the child. It has developed the 5R model (Read, Rhyme, Routines, Rewards, and Relationships) which stresses the importance of reading along with the child through ROR program.[2]

The National Survey of Children's Health (2011-2012) highlighted the disparity in reading between families who are below and above the national poverty levels. Children from families with median income below the national poverty level were at risk for academic underachievement.[3] To combat this problem, simple interventions implemented in Pediatric primary care practices to encourage literacy have had positive results. One study found that there was $40 \%$ more child literacy orientation in intervention families resulting in improved reading frequency and increased receptive and expressive vocabulary among older toddler children.[4] Another study which aimed to measure the impact of the ROR model reported that an increase in reading to children by their parents by one day, resulted in 8.6 points increase in receptive language and 4.3 points increase in expressive language in children belonging to 
lower socio-economic families.[5]

Multiple reports have confirmed that children who can read proficiently by the end of the third grade were more likely to be successful in their academic career. Also, the same reports have documented the disparity in reading proficiency between children from lower income families compared to the higher income families. Some states have a difference of about 36 points favoring children from the higher income families.[6-9] The data has also been reinforced through neuro-biology as evidenced in one study that found exposure to reading resulted in a positive correlation to activation of the language processing center in the brain which supports the mental imagery and comprehension in young children.[10]

\section{Baseline measurement}

For this project, we collected baseline measurement retrospectively by reviewing clinical encounters of 225 randomly selected patients aged six months to five years who had presented for well child checks in the 12 months prior to implementation of the project, specifically from March 2013 to February 2014. The data was pulled through the Electronic Medical Records (EMR) with the help of the health information team. Out of these 225 patients only 200 patients had responded to the three question paper survey which had asked specifically for three data points. 1) Did you receive an age appropriate book for your child? 2) Did your physician discuss about good reading habits? 3) How often do you read to your child? These surveys were short paper surveys given to the parents at the well checkup of their children. These surveys were usually administered by the medical assistants and collected at the end of the visit and stored in the clinic. After reviewing the data from the past two years, we noticed that there was a tremendous drop in the percentage of books handed out at well visits with only $30 \%$ of the eligible age group of the children ever receiving the books. Only one in four families received counsel from the primary care physicians about the importance of the reading and less than half of the families were reading to their children for more than four days a week.

See supplementary file: ds7519.pdf - "Baseline measurement"

\section{Design}

It was clear that the practice had to make a decision of streamlining the distribution of the books and also retraining the staff and the primary care residents. The stakeholders were identified and included nursing staff, medical assistants, resident primary care physicians, faculty physician champions, and the social worker. This Quality Improvement (QI) project was sponsored by the ROR and the American Board of Pediatrics. Our team comprised of a QI chair (physician), an administrator, two other medical providers, one resident, and a QI coach from ROR. With the involvement of the key stakeholders a clinic literacy workflow was developed. The team met every other month for six months and implemented a PDSA cycle. Three goals were established: 1 . To increase the rate of distribution of books at every well child visit (WCV) from six months to five years of age by at least $80 \%$. 2. To improve the rate of counseling given by the resident physicians to the families by at least $75 \%$. 3. To train our medical providers in giving good reading counsel to parents and explaining benefits of reading aloud to their children. 4 . To retrain the medical staff.

\section{Strategy}

PDSA Cycle 1: In the first cycle, we developed a literacy work flow which would enable the nursing staff and medical assistants while rooming in the patients, to choose an age appropriate book and to keep it along with the chart outside the room with the aim being that the physician would hand over the book to the child. This will then trigger the chain reaction of the resident physicians to counsel parent families on the importance of reading aloud every day to their children and in turn, this will increase the reading activity in the family. Three months after we started the project we saw a significant drop (69\%), in the parents receiving reading and literary advice from the resident physicians. The problem with the drop in the reading advice was due to the turnover of the resident physicians each year. Each year about a third of the residents graduate and new set of residents replace them.

PDSA Cycle 2: In order to train the new residents, an annual didactic was added in the residency lecture presentation open to all the residents and community physicians which were provided by both the faculty physician champion and the resident physician champion. The medical assistants and nursing staff were also retrained about the goals of the project and the importance of reading during one of the monthly clinical meetings.

PDSA cycle 3: In the third cycle, we created positive learning environments in the clinic waiting rooms and posters supporting reading in the exam rooms. There were volunteers who would come in and read to the children in the waiting rooms. Also, the placement of the books in the clinic was rearranged to the resident conference room so that it was easier for the nursing staff to remember to place the books with the chart and also to serve as a reminder for the residents to provide reading counsel to the parents and patients.

\section{Results}

We had our post intervention measurements at the end of each PDSA cycle as well as three months after the end of PDSA cycle 3. In total 210 surveys were collected from parents over an eight month period. The surveys had the same questions as the surveys in the baseline measurement. The questions inquired if the parent got a book, received good reading counsel, and the number of days they read to their child. The surveys were distributed by clinic administrative staff when rooming the patients in and were collected at the end of the visit. The rate of distribution of the books improved from $30 \%$ baseline to $96 \%$ within three months in the first PDSA cycle. Thereafter, it remained the same in the next two PDSA cycles. The percentage of families who received counseling about good reading habits improved also significantly from $26 \%$ baseline to $94 \%$ but three months after we started the project we saw a significant drop (69\%), in the parents receiving reading and literary 
advice from the resident physicians. After PDSA cycle 2, the percentage of families receiving counseling improved from $69 \%$ to $87 \%$. The percentage of families reading at least $20-30$ minutes for greater than four days in a week increased from $56 \%$ to $80 \%$ at the end of PDSA cycle 3.

See supplementary file: ds7517.pdf - "Clinic flow protocol and runcharts for ROR project"

\section{Lessons and limitations}

There were a few lessons we learned from this project. The resident physicians counseling about reading did not have a major impact on the clinic patient flow and the time for the appointment. The most significant barrier for this project was for the clinic administrative staff to remember to place a book with the chart. This was overcome by having the staff pick a book first before going to room in the patient. Another barrier encountered was for the residents to remember to talk about reading. Charts and posters supporting reading in the examination rooms, relocating the placement of age appropriate books to the resident conference room, and a reminder from supervising faculty, helped to overcome this problem. The three question survey from the family did not interfere with the physician time as it was done mainly by clinic administrative staff. Anecdotal data gathered about the project from resident physicians seemed to be positive as the chance to talk about literacy also paved way to discuss more healthy habits such as limiting screen time and nutrition etc.

\section{Conclusion}

Through this QI project, we were able to make changes to our workflow at clinic, educate our physicians, nurses, medical assistants, and administrative staff about the importance of reading which in turn helped our clinic families. This project had a positive impact on the rate of distribution of books, improving the reading counseling given to families by the resident primary care physicians, and also subsequently in the reading activity of the clinic families. The plan will be to continue to monitor the data by comparing the number of books distributed to the number of well child visits performed and to obtain cross sectional data from the families in a periodic manner. The ROR project could be easily replicated in other primary care practices as it had very minimal impact on flow of our busy clinics. The information from the surveys and the distribution of the books could also be a focus of discussion with patients and parents about their child's reading habits. This project is also sustainable as our primary care practice has continued to be active in this project in getting funds from community partners to distribute books to the children. Data from three months after our project showed that the primary care residents are providing reading counseling to the families and books are being distributed to the preschool age children. The clinic practice has plans to periodically assess the reading activity of our patients. Reading aloud is one of the most important activities a family can do together which can improve child's language, cognitive skills, and also may be the most critical to literacy acquisition.[11] Children who remain poor readers continue to have average levels of reading fluency.[12] Hence, it is very vital as primary care physicians we strive to influence our families to adopt optimal reading habits to impact the most important phase in a child's life in a positive way.

\section{References}

1. www.reachoutandread.org. accessed on 1/7/2016

2. https://www.aap.org/en-us/advocacy-and-policy/aap-healthinitiatives/EBCD/Pages/Five.aspx accessed on 1/7/2016.

3. Data Research Center for Child and Adolescent Health. 2011/12 National Survey of Children's Health. Available at: www. childhealthdata.org/browse/survey/results?q=2284\& $\mathrm{r}=$ $1 \& g=458$. Accessed January, 72016.

4. High PC, LaGasse L, Becker S, Ahlgren I,Gardner A. Literacy promotion in primary care pediatrics: can we make a difference? Pediatrics. 2000;105(4 pt 2):927-934

5. Mendelsohn AL, Mogilner LN, Dreyer BP,et al. The impact of a clinic-based literacy intervention on language development in inner-city preschool children. Pediatrics. 2001;107(1):130-134.

6. High PC; American Academy of Pediatrics, Committee on Early Childhood, Adoption, and Dependent Care and Council on School Health. School readiness. Pediatrics. 2008; 121(4): e1008-e1015.

7. The Annie E. Casey Foundation. (2010). Early Warning! Why Reading by the End of Third Grade Matters. Baltimore, MD: Author. Retrieved from www.aecf.org

8. The Annie E. Casey Foundation. (2013). Early Warning Confirmed: A Research Update on Third-Grade Reading. Baltimore, MD: Author. Retrieved from www.aecf.org;

9. Annie E. Casey Foundation. Early Reading Proficiency in the United States: A KIDS COUNT Data Snapshot. Baltimore, MD: Annie E. Casey Foundation; 2014. Available at: www.aecf.org $/ \mathrm{m} / \mathrm{resourcedoc/aecf-}$ EarlyReadingProficiency-2014.pdf. Accessed January,7 2016.

10. Hutton JS1, Horowitz-Kraus T2, Mendelsohn AL3, DeWitt T4, Holland SK5; C-MIND Authorship Consortium. Home Reading Environment and Brain Activation in Preschool Children Listening to Stories. Pediatrics. 2015 Sep;136(3):466-78. doi: 10.1542/peds.2015-0359.

11. http://www.reachoutandread.org/why-we-work/importance-ofreading-aloud/ accessed on 1/7/2016.

12. Joseph K. Torgesen. Avoiding the Devastating Downward Spiral :The Evidence That Early Intervention Prevents Reading Failure" American Educator Fall 2004 accessed: http://www.aft.org/periodical/americaneducator/fall-2004/avoiding-devastating-downward spiral\#sthash. 3hbxM7q8.dpuf

\section{Declaration of interests}

None to declare

\section{Acknowledgements}


Bobbi -Unbehaun-Wise (Medical Assistant), ROR, ICHD nurses and medical staff, MSU-Sparrow resident physicians.

\section{Ethical approval}

According to the Institutional Review Board at the Michigan State University "This project is deemed exempt as federal regulations for protection of human subjects will not apply to the project as this project is aimed to decrease the cost to the patient and health care in general." MSU IRB determined that the project did not need their approval 